\section{Oncocytic papillary cystadenoma of right laryngeal ventricle}

\author{
Tomasz Ścięgosz*, Renata Kwiatek, Izabela El-Hassanieh and \\ Piotr Ziółkowski
}

Department of Pathology, Wrocław Medical University, Poland

\section{Abstract}

A case of oncocytic papillary cystadenoma in a 72-year old woman, a rare tumor of laryngeal seromucinous glands of unclear nature is presented. The patient had a history of chronic inflammation of laryngeal mucosa and both her age and tumor location were typical. The lesion was resected transorally without complications. Histological findings are shown in the present study. The controversial status of oncocytic papillary cystadenoma as either a true neoplasm or a combination of metaplastic and hyperplastic changes, its resemblance to Warthin's tumor and optimal approach to treatment are discussed.
More Information

*Address for Correspondence: Tomasz Ścięgosz, MD., Department of Pathology, Wrocław Medical University, Marcinkowskiego 1, 50-368 Wrocław, Poland, Email: tomasz.sciegosz@umed.wroc.pl; ziolkows@interia.pl

Submitted: March 28, 2021

Approved: April 29, 2021

Published: April 30, 2021

How to cite this article: Ścięgosz T, Kwiatek R, El-Hassanieh I, Ziółkowski P. Oncocytic papillary cystadenoma of right laryngeal ventricle. Arch Case Rep. 2021; 5: 012-013.

DOI: 10.29328/journal.acr.1001048

Copyright: @ 2021 Ścięgosz T, et al. This is an open access article distributed under the Creative Commons Attribution License, which permits unrestricted use, distribution, and reproduction in any medium, provided the original work is properly cited.

Keywords: Larynx; Benign tumors; Oncocytic papillary cystadenoma

\section{Introduction}

Oncocytic papillary cystadenoma (OPC) of the larynx is a rare lesion of uncertain nature $[1,2]$. The $4^{\text {th }}$ edition of the WHO International Histological Classification of Tumors (IHCT) places it among laryngeal salivary gland tumors [3]. OPC usually occurs in patients in the sixth or seventh decade of life [3]. An association with a history of smoking is sometimes reported and both prolonged vocal stress and chronic inflammation have also been suggested as possible factors [1]. The lesion typically arises in the supraglottic region of larynx [3].

\section{Case presentation}

A 72-year-old woman developed a mass in her right laryngeal ventricle clinically diagnosed as a cyst. A range of blood tests and a chest radiograph were performed with unremarkable results. 15 months earlier the patient was diagnosed with chronic inflammation of laryngeal mucosa based on the biopsy of left laryngeal ventricle and histological findings.

The mass was removed through direct laryngoscopy under general anesthesia, Kleinsasser laryngoscope was utilized for the procedure. There were no complications and the patient was discharged the following day. Vocal cords movement and quality of the voice were excellent after the next 2 months following surgery.

The specimen was fixed in formalin, embedded in paraffin and then processed in a standard manner to perform
Check for updates

OPEN ACCESS histological slides stained with hematoxylin and eosin. Histologic examination revealed a well-defined multilocular cystic mass with short papillary projections and amorphous contents. The cysts lacked an apparent capsule (Figure 1). The lining consisted of columnar cells with abundant granular, eosinophilic cytoplasm, and bland predominantly cigar-shaped nuclei with inconspicuous nucleoli. The nuclei exhibited palisading along the lumen of the cysts and a second noncontinuous basal layer of cells could be observed (Figure 2). Some variation of nuclear morphology and arrangement was present in the papillary projections (Figure 3). Of note was the absence of lymphoid stroma which differentiates the lesion from Warthin's tumor (WT). The change was identified as oncocytic papillary cystadenoma.

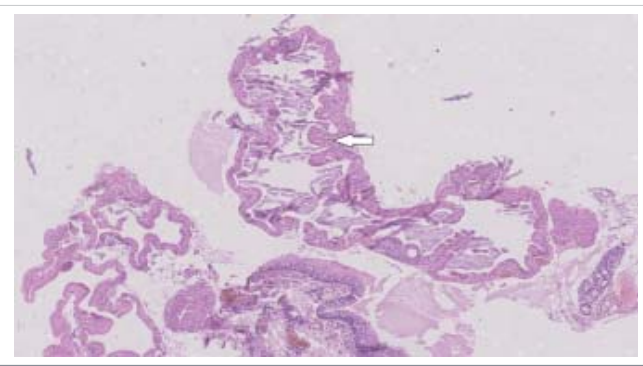

Figure 1: The lesion formed multiple well-defined cysts with amorphous contents and short intraluminal papillary projections (white arrow). Unchanged laryngeal epithelium and seromucinous gland are also pictured. HE staining, 50x. 


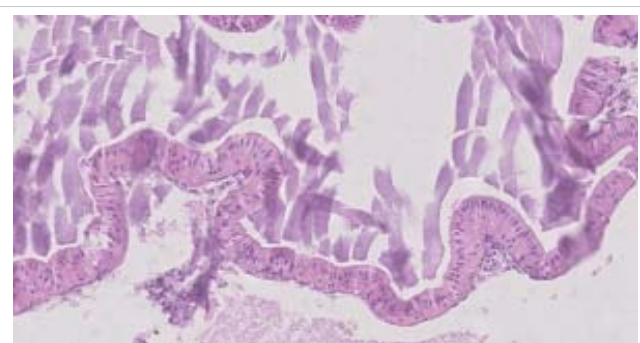

Figure 2: The cysts were lined with two layers of oncocytic cells; the continuous luminal layer of columnar cells with palisading cigar-shaped nuclei and the intermittent layer of basal cells with round nuclei. HE staining, 200x.

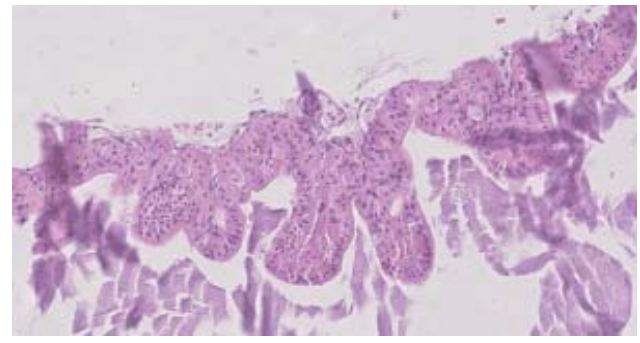

Figure 3: Some projections exhibited more round nuclei and less pronounced bilayered structure. HE staining. $200 x$

\section{Discussion}

Exact nature of oncocytic papillary cystadenoma is uncertain and the literature data is arguing for both benign neoplastic and a combination of metaplastic and hyperplastic origin [1]. International Histological Classification of Tumors simply classifies it as a salivary gland tumor [3]. Yamase and Putman, described a whole spectrum of oncocytic lesions in the total laryngectomy specimen, from simple oncocytic metaplasia of seromucinous glands to solid oncocytoma-like masses [4]. This may point to OPC being a part of continuum of metaplastic/hyperplastic changes rather than true neoplasm. OPC does not appear to be precursory to malignancy $[1,5]$. Several cases of concurrent OPC and laryngeal carcinoma have been described, but the two conditions are believed to have arisen independently, most likely due to common risk factors [4-6].

In the presented case the patient was in the typical age and the location of the lesion was likewise typical. Although it was unknown if the patient had a history of chronic smoking or vocal stress, the chronic inflammation of ventricular mucosa could have been a factor in the development of the change. The characteristic structure of epithelial lining of the cysts strongly resembles that commonly found in Warthin's tumor. Unlike Warthin's tumor the lesion showed no lymphoid stroma. Indeed, Stenner, et al. define OPC as a WT without the lymphatic component [5]. WT has been however proven to be of monoclonal nature [7] as opposed to unclear status of OPC.

In our case the change was managed via transoral resection which appears to be a sufficient approach in majority of such lesions [1,2]. Where specified in literature, the most common tool for excision of OPC and similar changes was a $\mathrm{CO}_{2}$ laser $[1,7,8]$. Cases with multiple lesions have also been described $[4,5]$ and so follow-up is still recommended as there is a possibility of subclinical foci of OPC which may manifest later following the excision of the main mass.

\section{References}

1. Salerno G, Mignogna C, Cavaliere M, D’Angelo L, Galli V. Oncocytic cyst of the larynx: an unusual occurrence. Acta Otorhinolaryngol Ital. 2007; 27: 212-215.

PubMed: https://pubmed.ncbi.nlm.nih.gov/17957853/

2. Kalfert D, Růžička J, Drsata J. Oncocytic papillary cystadenoma of the larynx: comparative study of 7 cases and review of the literature. Poster presented at: 3rd Congress of European ORL-HNS Prague. 2015.

3. Bloemena E, Bell D, Hunt JL. Oncocytic papillary cystadenoma. In: WHO Classification of Head and Neck Tumours, $4^{\text {th }}$ ed. Int Agency Res Cancer.2017: 99.

4. Yamase HT, Putman HC. Oncocytic papillary cystadenomatosis of the larynx. A clinicopathological entity. Cancer. 1979; 44: 2306-2311. PubMed: https://pubmed.ncbi.nlm.nih.gov/509398/

5. Stenner M, Müller KM, Koopmann M, Rudack C. Squamous cell carcinoma of the larynx arising in multifocal pharyngolaryngeal oncocytic papillary cystadenoma: a case report and review of the literature. Medicine (Baltimore). 2014; 93: e70.

PubMed: https://pubmed.ncbi.nlm.nih.gov/25211046/

6. Koh M, Nigam S. Oncocytic papillary cystadenoma of the larynx: a case report. Pathology. 2013; 45: 72.

7. Nisa L, Landis BN, Salmina C, Ailianou A, Karamitopoulou E, et al. Warthin's tumor of the larynx: A very rare case and systematic review of the literature. J Otolaryngol Head Neck Surg. 2015; 44: 16. PubMed: https://pubmed.ncbi.nlm.nih.gov/25964051/

8. Heyes R, Tomblinson CM, Lott DG. Multiple and Recurrent Oncocytic Cysts of the Larynx. Ear Nose Throat J. 2020; 99: NP54-NP55. PubMed: https://pubmed.ncbi.nlm.nih.gov/30987461/ 